\title{
MEDIDAS DE SALVAGUARDIA Y EXCLUSIONES REGIONALES EN LA JURISPRUDENCIA DE LA ORGANIZACIÓN MUNDIAL DE COMERCIO
}

\author{
SAFEGUARDS MEASURES AND REGIONAL EXCLUSIONS IN \\ THE WTO JURISPRUDENCE
}

\author{
Cristián Delpiano Lira*
}

\begin{abstract}
RESUMEN: El presente artículo analiza la relación entre las medidas de salvaguardia impuestas de conformidad con las normas de la Organización Mundial de Comercio, y la pretendida facultad que tienen los Estados miembros de la OMC de excluir a los socios de acuerdos de libre comercio de dichas medidas. Luego de identificar la práctica en diversos acuerdos de libre comercio, se revisará la respuesta de los Grupos Especiales y del Órgano de Apelación de la OMC. En este análisis, se intentará desarrollar el contenido de la doctrina del paralelismo que ha sido desarrollada por el Órgano de Apelación.
\end{abstract}

Palabras clave: Organización Mundial de Comercio, Acuerdo sobre Salvaguardias, Doctrina de paralelismo, Acuerdos de Libre Comercio, Artículo XXIV del GATT.

ABSTRACT: This article deals with the relationship between WTO safeguards and the exclusion of WTO Members parties of a free trade agreement from those measures. It analyses the practice on several free trade agreements, and the answer from the panels and the Appellate Body of the WTO, including an assessment of the parallelism doctrine developed by the Appellate Body.

Key words: World Trade Organization, Safeguards Agreements, Parallelism Doctrine, Free trade agreements, GATT Article XXIV.

\section{INTRODUCCIÓN}

Las medidas de salvaguardia se definen como medidas de defensa comercial que tienen por objeto hacer frente a un aumento imprevisto de las importaciones cuando dichas importaciones causan o amenazan causar un daño grave a los productores nacionales de productos similares o directamente competidores en ese territorio. Estas medidas pueden adoptar la forma de un aumento de aranceles por sobre los compromisos $\mathrm{OMC}^{1}$, o bien la forma de una restricción cuantitativa a la importación del producto de que se trate.

* Doctor en Derecho por la Universidad de Salamanca, España. Profesor de Derecho Internacional Público de la Universidad Católica del Norte y Coordinador del Centro de Estudios en Derecho de los Recursos Naturales (CEDRENA). Co-Rapporteur of the Study Group on Preferential Trade and Investment Agreements, International Law Association. Este trabajo ha sido elaborado como parte del proyecto de investigación de iniciación patrocinado por Fondecyt bajo el número 11130657. Dirección postal: Avda. Angamos 0610, Antofagasta, Chile. Dirección electrónica: cdelpiano@ucn.cl

${ }^{1}$ Dentro de los compromisos arancelarios que los Estados miembros suscriben en el marco de la OMC, se debe distinguir entre los "aranceles consolidados" (que constituyen el tope que un Estado puede exigir en las importaciones en régimen Nación Más Favorecida) de los "aranceles aplicados" (que constituye el arancel efecti- 
Delpiano Lira, Cristián — "Medidas de salvaguardia y exclusiones regionales en la jurisprudencia ..."

A diferencia de otras medidas de defensa comercial -como las del artículo VI (medidas antidumping) y el caso de las medidas compensatorias por subvenciones prohibidas otorgadas en el país exportador-, las medidas de salvaguardia no responden a casos de competencia desleal, sino que a casos de medidas urgentes y temporales para recuperar la competitividad de los productores internos frente al eventual daño que pueda producir dicho aumento imprevisto de importaciones.

La regulación general en materia de salvaguardias se encuentra contenida en el artículo XIX del Acuerdo General sobre Aranceles Aduaneros y Comercio (“GATT”), y su regulación específica se encuentra en el denominado Acuerdo sobre Salvaguardias de la OMC, resultante de la Ronda Uruguay de Negociaciones Comerciales Multilaterales.

Con carácter general, las normas de la OMC exigen que las medidas de salvaguardia se apliquen "al producto importado independientemente de la fuente de donde proceda" lo que sugiere que deben aplicarse sobre la base del principio Nación Más Favorecida, impidiendo la selectividad de países al momento de adoptar una medida de salvaguardia.

Sin embargo, diversos acuerdos de libre comercio suscritos por Chile contienen disposiciones que obligan a excluir a sus socios comerciales de este tipo de medidas ${ }^{3}$. Esta cuestión contradice, al menos en apariencia, la norma del Acuerdo sobre Salvaguardias señalado, dado que al obligar la exclusión de socios comerciales que a la vez sean miembros de la OMC, se estaría seleccionando la procedencia de los productos cuya medida de salvaguardia se impone $e^{4}$.

Por su parte, esta norma no debe entenderse al margen de la regulación de las zonas de libre comercio dentro del marco de las normas OMC. En efecto, el artículo XXIV.8 letra b) del GATT define una zona de libre comercio como "un grupo de dos o más territorios aduaneros entre los cuales se eliminen los derechos de aduana y las demás reglamentaciones comerciales restrictivas (excepto, en la medida en que sea necesario, las restricciones autorizadas en virtud de los artículos XI, XII, XIII, XIV, XV y XX ${ }^{5}$ ) con respecto a lo esencial de los intercambios comerciales de los productos originarios de los territorios constitutivos de dicha zona de libre comercio". Es relevante señalar en este punto, que el artículo XXIV del GATT constituye una justificación para dejar de aplicar las normas multilaterales a este tipo de acuerdos - cláusula Nación Más Favorecida ${ }^{6}$, en la medida que cumplan con

vamente percibido por el Estado en la importación del producto). La medida de salvaguardia supone aplicar un arancel más alto que el consolidado.

2 Artículo 2.2 del Acuerdo sobre Salvaguardias de la OMC.

3 Es el caso específico de los acuerdos suscritos con Estados Unidos, Canadá, Centroamérica, México y Perú, en este último caso bajo ciertas condiciones. Hay que señalar en este punto que este es un problema de diversos acuerdos de libre comercio notificados bajo el amparo del artículo XXIV del GATT, especialmente en el caso de Estados Unidos.

4 Los únicos casos de selectividad permitidos en materia de salvaguardias por normas OMC se encuentran en el artículo 9 del Acuerdo sobre Salvaguardias -relativo al trato especial y diferenciado respecto de los países en desarrollo miembros-, y la disposición del artículo 16 del Protocolo de Adhesión de China.

5 Esto es, con carácter general, las restricciones cuantitativas y las excepciones generales del artículo XX.

${ }^{6}$ La cláusula Nación Más Favorecida se encuentra definida en el artículo I del GATT como una obligación general de los Estados miembros de la OMC, consistente en que "[...] cualquier ventaja, favor, privilegio o inmunidad concedido por una parte contratante a un producto originario de otro país o destinado a él, será con- 
los requisitos y condiciones establecidos en esta disposición. Sin embargo, sigue abierta la cuestión de si la facultad de discriminar inherente en el artículo XXIV se extiende hasta el punto de permitir salvaguardias selectivas que eximan a las demás partes del acuerdo de libre comercio ${ }^{7}$.

Según veremos, dentro del sistema GATT/OMC no existe un criterio definido para resolver el problema de la exclusión de las medidas de salvaguardia globales a los socios de un acuerdo de libre comercio, así como tampoco existe un criterio definido en el seno del Mecanismo de Solución de Controversias que permita determinar los estándares de implementación de una medida de salvaguardia, y las condiciones para poder eximir a un socio comercial de este tipo de medidas.

En consecuencia, la relación entre el artículo XIX del GATT, el Acuerdo sobre Salvaguardias de la OMC y el artículo XXIV del GATT serán tratados en este artículo. En este sentido, luego de sistematizar la práctica existente en acuerdos de libre comercio y los debates que dicha práctica sugiere (apartado segundo), identificaremos los criterios propuestos por los Grupos Especiales de la OMC (apartado tercero), y su respuesta en el Órgano de Apelación (apartado cuarto).

\section{LA RELACIÓN ENTRE EL ARTÍCULO XIX Y XXIV DEL GATT Y LA PRÁCTICA EN LOS ACUERDOS DE LIBRE COMERCIO}

Frente a la formación de un acuerdo de libre comercio, se pueden identificar diversas familias de normas relativas a la situación de salvaguardias globales ${ }^{8}$, y su relación con los socios comerciales. Una primera posibilidad consiste en que los Estados parte de un acuerdo de libre comercio conserven los derechos establecidos en los acuerdos OMC relativos a la regulación sobre salvaguardias, lo que implica que en la imposición de dicha medida de manera global se deben incluir los productos provenientes de los territorios de los socios de un acuerdo de libre comercio, salvo que las normas OMC permitan su exclusión. Sin embargo, y siguiendo la tendencia marcada por el NAFTA ${ }^{9}$, muchos Estados han introducido exenciones a los restantes Estados parte de un acuerdo de libre comercio de la aplicación de

cedido inmediata e incondicionalmente a todo producto similar originario de los territorios de todas las demás partes contratantes o a ellos destinado".

7 SYKes (2006) p. 227.

8 Se debe distinguir la situación de la exclusión de socios comerciales de medidas de salvaguardias globales, respecto de la inclusión de medidas de salvaguardia bilaterales en los acuerdos de libre comercio. En este sentido, la mayoría de los acuerdos de libre comercio adoptan mecanismos bilaterales específicos en materia de salvaguardias, que buscan suspender temporalmente las concesiones en caso de daño grave o amenaza de daño grave a la industria doméstica, dentro del marco del propio acuerdo de libre comercio. Aun cuando la naturaleza exacta de las medidas bilaterales de salvaguardia varía dependiendo del acuerdo de libre comercio que se trate, ellos comparten la característica común que la concesión realizada bajo el amparo del acuerdo de libre comercio puede ser temporalmente suspendida en contra de otro Estado parte de dicha zona. Además, muchos acuerdos de libre comercio introducen sistemas de salvaguardia específicos para determinados sectores, tales como agricultura e industria textil [AHN (2008) p. 115].

9 El artículo 802 del NAFTA establece que "Las Partes conservan sus derechos y obligaciones conforme al Artículo XIX del GATT o a cualquier otro acuerdo de salvaguardas suscrito al amparo del mismo, excepto los referentes a compensación o represalia y exclusión de una medida en cuanto sean incompatibles con las disposi- 
DelpiAno LiRA, Cristián — "Medidas de salvaguardia y exclusiones regionales en la jurisprudencia ..."

medidas de salvaguardia globales bajo el amparo del sistema $\mathrm{OMC}^{10}$. Estas disposiciones pueden presentar tres formas distintas. La primera y más liberal, dice relación con aquellas normas que obligan a los Estados parte de un acuerdo de libre comercio a excluir a la otra parte de una medida de salvaguardia global, con independencia de la incidencia que las importaciones provenientes de dicho Estado puedan provocar en el daño o amenaza de daño grave a la rama de producción nacional ${ }^{11}$. Esta fórmula también se puede presentar en el sentido de prohibir la imposición de una medida de salvaguardia global a las demás partes de un acuerdo de libre comercio, que es el caso de algunos acuerdos de libre comercio suscritos por Singapur ${ }^{12}$.

Una segunda opción consiste en la obligación de excluir a los socios comerciales de las medidas de salvaguardias globales, cuando las importaciones de dichos países no causan o amenazan causar grave daño, entregando la carga de la prueba de la constatación contraria al Estado que impone la medida de salvaguardia ${ }^{13}$. El mismo efecto se produce en aquellos casos en que las partes quedan obligadas a excluirse mutuamente de una medida de salvaguardia, salvo que las importaciones de la otra parte sean de un porcentaje relevante del

ciones de este artículo. Cualquier Parte que aplique una medida de emergencia conforme a aquellas disposiciones excluirá de la medida las importaciones de bienes de cada una de las otras Partes, a menos que:

(a) las importaciones de una Parte, consideradas individualmente, representen una participación sustancial en las importaciones totales; $y$

(b) las importaciones de una Parte consideradas individualmente o, en circunstancias excepcionales, las importaciones de varias Partes consideradas en conjunto, contribuyan de manera importante al daño serio o amenaza del mismo causado por dichas importaciones" (Cursivas añadidas). Cabe consignar que la misma norma aparece en el artículo F-02 del Acuerdo de Libre Comercio entre Chile y Canadá y en el artículo 6-03 del acuerdo entre Chile y México. Cuestión distinta ocurre en el acuerdo entre Chile y Estados Unidos, en el cual se conservan los derechos y obligaciones emanadas del artículo XIX del GATT y del Acuerdo sobre Salvaguardias de la OMC. A mayor abundamiento, el artículo 8.6 párrafo 2 del Acuerdo establece que "Este Acuerdo no confiere derechos u obligaciones adicionales para las Partes con respecto a las acciones tomadas de conformidad con el Artículo XIX del GATT 1994 y con el Acuerdo sobre Salvaguardias" (Véase GanTz (2009) p. 119; MATHIS (2002) p. 183 y ss.).

10 Ahn (2008) p. 116.

11 Es el caso, por ejemplo, del artículo 2.13.2 del acuerdo entre la Asociación Europea de Libre Comercio y Hong Kong, China, que señala, inter alia, "In taking global safeguard measures, a Party shall, [...], exclude imports of originating products from another Party referred to in this paragraph, in particular [...]" (Cursiva añadida).

12 Véase, por ejemplo, el acuerdo de libre comercio entre Singapur y Australia, cuyo artículo 9 establece que "A Party shall not initiate or take any safeguard measure within the meaning of the WTO Agreement on Safeguards against the goods of the other Party from the date of entry into force of this Agreement" (resaltado añadido). Lo mismo ocurre en el acuerdo de libre comercio entre Singapur y Nueva Zelanda, cuyo artículo 8 establece que "Neither Party shall take safeguard measures against goods originating in the other Party from the date of entry into force of this Agreement". La nota número cinco incluida en dicha norma agrega que "Safeguard measures' means those measures falling within the ambit of the WTO Agreement on Safeguards".

13 Un ejemplo de esta cláusula se puede encontrar en el artículo 19 del Acuerdo de Libre Comercio entre la Asociación Europea de Libre Comercio y Albania, que establece: "The rights and obligations of the Parties in respect of general safeguards shall be governed by Article XIX of GATT 1994 and the WTO Agreement on Safeguards. In taking measures under these WTO provisions, a Party shall exclude imports of an originating product from one or several Parties if such imports do not in and of themselves cause or threaten to cause serious injury. The Party taking the measure shall demonstrate that such exclusion is in accordance with WTO jurisprudence". 
total de las importaciones, y que contribuyan de manera relevante al daño o amenaza de daño de los productores nacionales de productos similares o directamente competidores ${ }^{14}$.

Por último, se ha adoptado otro tipo de normas que, si bien no obligan a eximir de este tipo de medidas, establecen la facultad de excluir a la otra parte del acuerdo de libre comercio, en la medida que las importaciones de los bienes originarios de la otra parte no son causa substancial de un daño grave o amenaza de daño grave ${ }^{15}$.

En este último caso, la norma se vuelve en algún sentido más débil, transformando una obligación en una simple facultad, o un derecho de las partes de excluir a la otra de la medida de salvaguardia global.

Un último caso particular se puede identificar a partir del acuerdo de libre comercio entre Chile y Perú, que dispone que cualquier excepción en la aplicación de medidas de salvaguardia que se otorgue por una parte a un país no parte se extenderá, en las circunstancias y condiciones que se otorgó la excepción, automáticamente a la otra parte, de forma tal que se debe aplicar la cláusula Nación Más Favorecida en la aplicación de una medida de salvaguardia por alguno de ellos.

En consecuencia, y a diferencia de acuerdos que obligan o permiten excluir a una parte de un tratado de libre comercio solo bajo ciertas circunstancias, algunos siempre excluirán a los socios de un acuerdo de libre comercio de las medidas de salvaguardias adoptadas bajo el amparo de la OMC, siendo irrelevante la situación económica subyacente ${ }^{16}$.

De esta manera, diversos países han sido excluidos de medidas de salvaguardia globales, provocando a su vez diferencias en el seno del Órgano de Solución de Diferencias, que han sometido a debate la relación entre el artículo XIX y el artículo XXIV del GATT. El Órgano de Apelación, por su parte, ha evadido la cuestión a través del desarrollo de la doctrina del paralelismo, según veremos infra.

Desde el punto de vista de la regulación multilateral en materia de formación de acuerdos de libre comercio, el artículo XXIV del GATT exige la eliminación de los derechos de aduana y de las demás reglamentaciones comerciales restrictivas, con las excepciones señaladas dentro del paréntesis. En este sentido, se encuentran incorporadas dentro de las excepciones las restricciones cuantitativas y las excepciones generales del artículo XX,

${ }_{14}$ Véase, por ejemplo, el artículo 4.6 del Acuerdo de Libre Comercio entre Canadá e Israel.

15 Tal es el caso, por ejemplo, del artículo 7.5 del acuerdo entre Estados Unidos y Singapur, que establece que "Each Party retains its rights and obligations under Article XIX of GATT 1994 and the WTO Agreement on Safeguards. This Agreement does not confer any additional rights or obligations on the Parties with regard to global safeguard measures, except that a Party taking a global safeguard measure may exclude imports of an originating good from the other Party if such imports are not a substantial cause of serious injury or threat thereof. Cabe consignar que ello ocurre en buena parte de los acuerdos de libre comercio suscrito por Estados Unidos. Véase en este sentido AHN (2008) p. 116. Sobre comentarios generales al acuerdo entre Estados Unidos y Singapur puede verse GanTZ (2009) p. 249 y ss.

16 También cabe tener presente que muchos acuerdos establecen medidas de salvaguardia especiales para bienes agrícolas, así como para textiles y vestidos. En el caso del acuerdo de libre comercio entre Chile y Corea, se establece una cláusula sobre medidas de emergencia en materia agrícola, en la cual se establece no solo los conceptos de daño grave o amenaza de daño grave, sino que además se introduce el concepto de "alteraciones en los mercados de productos similares o competidores directos", sin que se establezca un concepto, a nivel multilateral ni bilateral acerca de su contenido. Esta falta de precisión de su contenido puede generar dudas acerca de su real aplicación [AHN (2008) p. 117]. 
Delpiano LiRA, Cristián — "Medidas de salvaguardia y exclusiones regionales en la jurisprudencia ..."

mientras que se excluyen de las excepciones las medidas de defensa comercial (esto es, las medidas antidumping del artículo VI y las medidas de salvaguardia del artículo XIX), y las excepciones relativas a seguridad del artículo XXI del GATT.

De esta manera, la falta de inclusión del artículo XIX dentro de las excepciones del artículo XXIV.8, y sus consecuencias en las condiciones de aplicación de salvaguardias globales a las partes en los acuerdos de libre comercio, supone la necesidad de cuestionarse acerca de si acaso existe o no la obligación (o facultad) de un Estado parte de un acuerdo de libre comercio de excluir a los restantes de las medidas de salvaguardia globales, o si bien las normas multilaterales no pueden ser interpretadas en el sentido de permitir que los Estados parte de un acuerdo de libre comercio se excluyan mutuamente de una medida de salvaguardia global ${ }^{17}$. Esta cuestión lleva a identificar tres posturas diferentes ${ }^{18}{ }^{19}$, que se estructuran sobre la base del debate que se podría denominar "facultad vs. obligación" 20 .

Una primera postura señala que sigue siendo obligatorio aplicar a las salvaguardias globales el régimen Nación Más Favorecida, incluso para los asociados en acuerdos de libre comercio. Conforme a esta tesis, el listado de excepciones del artículo XXIV del GATT es meramente ilustrativo, por lo que el artículo XXIV no exime del principio básico del régimen Nación Más Favorecida para las medidas de salvaguardia. En otras palabras, cualquiera medida de esta naturaleza debe ser adoptada sin discriminación alguna de si se trata de un socio en un acuerdo de libre comercio o no. Ello también responde a la tesis que no se puede invocar el artículo XXIV como justificación para el incumplimiento de otras normas del GATT $^{21}$, incluyendo dentro de este marco el Acuerdo sobre Salvaguardias.

A mayor abundamiento, al ser las salvaguardias medidas urgentes y temporales, permiten ser aplicadas al margen del artículo II del GATT así como de otras disposiciones, en forma excepcional. De manera que si no es necesario aplicar medidas de este tipo contra las importaciones de las partes en un acuerdo de libre comercio, tales medidas tampoco pueden aplicarse contra terceros países. De lo contrario, existiría una discriminación entre las partes del acuerdo y los terceros Estados miembros de la OMC. Así pues, debe comprenderse que las medidas de salvaguardia deben adoptarse sobre una base Nación Más Favorecida sin hacer discriminación alguna entre las partes en el acuerdo de libre comercio

17 Pauwelyn (2004) p. 109.

18 Las salvaguardias se centran en las fluctuaciones del volumen comercial cuya rapidez y magnitud no pueden hacer pensar razonablemente que los productores vayan a adaptarse a esos nuevos flujos comerciales. En tales casos, las normas de la OMC y de la UE permiten imponer restricciones de corta duración a la importación para aliviar temporalmente a la industria y darle la oportunidad de adaptarse al cambio repentino. Esta oportunidad temporal va unida a una obligación explícita de reestructuración [COMisión Europea (2006) p. 4].

19 Informe del Grupo de Negociación sobre las Normas: Compendio de Cuestiones Relacionadas con los Acuerdos Comerciales Regionales (TN/RL/W/8/Rev.1), de 1 de agosto de 2002, párrafo 75. Cabe destacar que no existe indicación alguna en los antecedentes de la redacción del artículo XXIV del GATT 1947 o en las actas de la Secretaría sobre la razón de no incluir un disposición correspondiente al artículo XIX en la lista de excepciones del párrafo 4 del artículo 44 de la Carta de la fallida Organización Internacional del Comercio o en el actual párrafo 8 del artículo XXIV (Véase al respecto la Nota de la Secretaría relativa al artículo XXIV del GATT, MTN.GNG/NG7/W/13/Add.1, de 10 de julio de 1988, párrafo 3).

20 "May versus Must" debate, en Gobbi Estrella y Horlick (2006) p. 121.

21 Véase en este sentido el Informe del Grupo de Trabajo sobre las Comunidades Económicas Europeas Acuerdos con Islandia, L/3902, de 19 de octubre de 1973, párrafos 34 y 35. 
y terceros países, como se dispone en el párrafo 2 del artículo 2 del Acuerdo sobre Salvaguardias $^{22}$.

Otro argumento a favor de esta tesis sostiene que, si se examina el sentido del artículo XIX del GATT (omitido en las excepciones contempladas en el artículo XXIV) versus las disposiciones relativas a la imposición de restricciones cuantitativas a la importación de productos (artículos XI y XII del GATT, incluidos en las excepciones contempladas en el artículo XXIV), se puede señalar que en ambos casos los efectos son los mismos, aunque los fundamentos para su imposición sean diversos. En efecto, los artículos XI y XII contemplan situaciones externas al marco jurídico del GATT ${ }^{23}$, en tanto que la excepción del artículo XIX implica otorgar un mecanismo para hacer frente a circunstancias que son consecuencia de las propias medidas de liberalización adoptadas bajo el amparo del GATT ${ }^{24}$. En otras palabras, las restricciones cuantitativas permitidas bajo el amparo de los artículos XI y XII del GATT se justifican por circunstancias que no solo son ajenas a la voluntad del Estado, sino que además son ajenas a la propia normativa OMC, como las restricciones a las exportaciones que persigan evitar la escasez de productos en el país exportador, o bien que tengan como fundamento salvaguardar el equilibrio sobre la balanza de pagos por parte del Estado. En el caso de las salvaguardias, se generan mayormente por efectos de decisiones previas de política comercial adoptada por el Estado en cuestión. Así, la propia liberalización comercial generada a partir de la formación de un acuerdo de libre comercio permitido bajo el amparo del artículo XXIV del GATT puede incentivar un aumento en las importaciones de un producto determinado que cause o amenace causar daño a alguna rama de producción nacional, por lo que será por efectos de la propia liberalización producida bajo el amparo del GATT la aplicación de la medida. En este sentido, resulta contradictorio que el Estado causante del aumento de las importaciones sea excluido de la medida de salvaguardia global.

En la práctica del GATT, aun cuando no se había alcanzado un acuerdo en torno a la relación entre las normas de los artículos XXIV y XIX del GATT, en diversos casos las medidas de salvaguardia adoptadas bajo el amparo del artículo XIX se han aplicado sobre la base Nación Más Favorecida, incluyendo las importaciones entre las partes contratantes de un acuerdo de libre comercio ${ }^{25}$. Así, se puede sostener que antes de la formación de la

22 Este mismo criterio se aplicaría a la aplicación de medidas antidumping. Véase la Comunicación del Japón al Comité de Acuerdos Comerciales Regionales: Las Demás Reglamentaciones Comerciales, WT/REG/W/29 de 29 de julio de 1998, párrafo 10. Por el contrario, en el asunto Argentina - Calzado, las CCEE señalaron que "las medidas de salvaguardia constituyen un instrumento excepcional de urgencia, de carácter temporal, limitadas a un producto determinado, y que como tales no afectan al establecimiento ni a la naturaleza de una unión aduanera o de una zona de libre comercio. En virtud del artículo XXIV del GATT, los miembros de una unión aduanera o de una zona de libre comercio pueden decidir si, al aplicar una medida de salvaguardia con arreglo al artículo XIX del GATT de 1994 y al Acuerdo sobre Salvaguardias, eximirán de la misma a otros miembros de la unión aduanera o de la zona de libre comercio" (Argentina - Medidas de Salvaguardia Impuestas a las Importaciones de Calzado (WT/DS121/R), Informe del Grupo Especial de 25 de junio de 1999, párrafo 8.94).

23 Prevenir el desabastecimiento del producto a nivel interno y proteger la balanza de pagos.

24 Véase en este sentido la Comunicación de Australia al Comité de Acuerdos Comerciales Regionales, WT/ REG/W/18 de 17 de noviembre de 1997, párrafos 18 y 19.

25 Informe del Grupo de Trabajo sobre el Acuerdo de Libre Comercio entre Estados Unidos y Canadá, L/6927 de 31 de octubre de 1991, párrafo 63. 
OMC, el artículo XXIV no permitía la selectividad en la aplicación de medidas de salvaguardia. Según la redacción de la norma en el acuerdo de libre comercio, puede diluir el principio de no discriminación y Nación Más Favorecida en la aplicación de restricciones basadas en el artículo XIX, lo que a su vez puede significar la adopción de una postura específica sin que las negociaciones comerciales lo hubiesen resuelto ${ }^{26}$.

Una segunda postura sostiene que está permitido aplicar medidas de salvaguardia a los asociados en acuerdos de libre comercio, solo cuando así lo permite el derecho internacional en materia de tratados multilaterales. En este sentido, las partes en los tratados multilaterales están facultadas para alterar sus derechos y obligaciones recíprocos siempre que no menoscaben los derechos de terceros Estados. Esta interpretación, sin embargo, lleva a la cuestión de si una parte puede exonerar a sus asociados de una medida de salvaguardia global haciéndolo depender de si sus importaciones representen o no una "parte sustancial" del total de sus importaciones y hayan contribuido al "daño grave", o también si las salvaguardias pueden imponerse al comercio intrarregional solamente cuando se ha determinado que el daño se debe a la reducción de derechos de aduana establecida en el acuerdo de libre comercio, según se señaló supra ${ }^{27}$. En este sentido, una postura más radical sostiene que la omisión del artículo XIX de los requisitos del párrafo 8 letra b) del artículo XXIV quiere señalar que las partes de un acuerdo de libre comercio tienen la libertad para eximir a dichos miembros de las posibles restricciones impuestas por el artículo $\mathrm{XIX}^{28}$, aun cuando las importaciones provenientes del Estado parte de un acuerdo de libre comercio representen una parte sustancial de las importaciones y que hayan contribuido al grave daño.

Por contrapartida, otra postura sostiene que las medidas de salvaguardia aplicadas de conformidad con el artículo XIX no pueden ni deben ser aplicadas a otros miembros de un acuerdo de libre comercio, dado que es parte de las razones para la creación de una zona de libre comercio que los miembros que lo forman acepten que cada miembro pueda ser un productor más eficiente en diversos productos, siendo contradictoria la institucionalización o mantención de un mecanismo de protección frente a esta eficiencia ${ }^{29}$.

\footnotetext{
26 Esta discusión se presentó en el análisis de compatibilidad del Acuerdo de Libre Comercio entre Estados Unidos y Canadá, específicamente en relación con el artículo 1102.1 de dicho acuerdo. La norma señala que "With respect to an emergency action taken by a Party on a global basis, the Parties shall retain their respective rights and obligations under Article XIX of the General Agreement on Tariffs and Trade subject to the requirement that a Party taking such action shall exclude the other Party from such global action unless imports from that Party are substantial and are contributing importantly to the serious injury or threat thereof caused by imports. For purposes of this paragraph, imports in the range of five percent to ten percent or less of total imports would normally not be considered substantial'.

27 Véase la nota al pie 48 del Informe del Grupo de Negociación sobre las Normas: Compendio de Cuestiones Relacionadas con los Acuerdos Comerciales Regionales (TN/RL/W/8/Rev.1), de 1 de agosto de 2002.

28 Informe del Grupo de Trabajo sobre las Comunidades Económicas Europeas Acuerdos con Islandia, L/3902, de 19 de octubre de 1973, párrafo 35.

29 Informe del Grupo de Trabajo sobre el Acuerdo de Libre Comercio entre Estados Unidos y Canadá, L/6927 de 31 de octubre de 1991, párrafo 63. Una expresión de esta tesis se puede encontrar en la disposición del artículo 2.13.2 del Acuerdo de Libre Comercio entre la Asociación Europea de Libre Comercio y Hong Kong, China, que establece que "[...] In taking global safeguard measures, a Party shall, consistent with its obligations under the WTO Agreements, exclude imports of originating products from another Party referred to in this paragraph, in particular if such imports do not in and of themselves cause or threaten to cause serious injury (resaltado añadido).
} 
A mayor abundamiento, la práctica corriente en los casos de excepciones a los principios generales es considerar que la lista de las "demás reglamentaciones comerciales" es exhaustiva ${ }^{30}$. De esta manera, si entendemos que las medidas de salvaguardias son reglamentaciones comerciales restrictivas no incluidas dentro de aquellas que pueden ser mantenidas de conformidad con el párrafo 8 del artículo XXIV, entonces ellas deben ser eliminadas respecto a "lo esencial de los intercambios comerciales" entre las partes ${ }^{31}$. En otras palabras, las exclusión del artículo XIX de las excepciones del artículo XXIV supone, contrario sensu, que dicha reglamentación comercial ${ }^{32}$ debe ser suprimida entre la partes, lo que supondría entonces que los socios en acuerdos de libre comercio deben ser excluidos de esta clase de medidas globales. Cabe mencionar que lo mismo puede sostenerse respecto de las medidas compensatorias, así como las medidas antidumping.

Sin embargo, se debe señalar que existen fuertes argumentos para sostener que la lista del artículo XXIV no puede ser exhaustiva. En efecto, al no estar incluido el artículo XXI del GATT $^{33}$ dentro de las excepciones, no está justificado de modo alguno que deban excluirse las excepciones relativas a la seguridad a los restantes socios de un acuerdo de libre comercio. Una interpretación contraria exigiría que las partes en estos acuerdos eliminaran las reglamentaciones permitidas en el artículo XXI contra otras partes en estos acuerdos, incluso si fueran indispensables para la seguridad nacional de los Estados que se trate, interpretación que sería poco realista. De esta manera, se debe examinar si hay excepciones que no sean las enumeradas entre paréntesis en el párrafo 8 del artículo XXIV, a la luz de los fines que persiguen otras disposiciones de la OMC. Al analizar esta cuestión, se debe tener presente que se debe evitar en toda la medida posible los efectos desfavorables sobre terceros países ${ }^{34}$.

Otro argumento para sostener la exclusión de socios comerciales, señala que cuando los miembros establecen una zona de libre comercio intentan aplicar medidas de integración económica que van más allá de las que promueven en sus relaciones comerciales normales, proponiéndose lograr niveles de eficiencia en el mercado interno que se consideran inalcanzables a través de otros medios, por lo que parece extraño que las partes recurran al artículo XIX contra las demás partes para impedir ese nivel de eficiencia. A mayor abundamiento, las partes pueden considerar un período de transición durante el cual puedan aplicar medidas de salvaguardia, pero una vez que el acuerdo adquiere plena vigencia, la evolución imprevista de las circunstancias ya no debe ser un factor determinante en un acuerdo de libre comercio, por lo que sería redundante recurrir al artículo XIX ${ }^{35}$.

${ }^{30}$ En este sentido, Argentina argumentaba que la aplicación de medidas de salvaguardia en el marco de la unión aduanera del MERCOSUR resulta incompatible con el propósito del párrafo 8 del artículo XXIV del GATT (Argentina - Calzado (WT/DS121/R), Informe del Grupo Especial, párrafo 8.93).

${ }^{31}$ Gobbi Estrella y Horlick (2006) p. 147.

32 Existe poco margen para sostener que no se trata de una reglamentación comercial [LOCKHART y MiTCHELL (2005) p. 238].

${ }^{33}$ El artículo XXI del GATT permite adoptar medidas comerciales bajo el fundamento de la seguridad nacional, en las hipótesis previstas en dicha norma.

${ }^{4}$ Véase la Comunicación del Japón al Comité de Acuerdos Comerciales Regionales: Las Demás Reglamentaciones Comerciales, WT/REG/W/29 de 29 de julio de 1998, párrafo 8.

${ }^{35}$ Véase en este sentido la comunicación de Australia al Comité de Acuerdos Comerciales Regionales, WT/ REG/W/18 de 17 de noviembre de 1997, párrafo 21. 
El asunto Turquía-Textiles -leading case en la interpretación relativa a los términos del artículo XXIV del GATT- sugiere una lectura contradictoria en esta cuestión. En efecto, por una parte los miembros de una unión aduanera pueden aplicar, cuando sea necesario, determinadas reglamentaciones comerciales restrictivas permitidas en virtud del los artículos XI a XV y el artículo XX del GATT, de manera que se advierte una adopción por parte del Órgano de Apelación de un criterio facultativo en la materia ${ }^{36}$. Sin embargo, una segunda lectura puede sugerir que no permite las salvaguardias que excluyan las importaciones regionales, debido a los requisitos exigidos por el informe para la introducción de medidas incompatibles con otras disposiciones del GATT -esto es, demostrar que la medida se ha introducido con ocasión de la formación de una unión aduanera, y que la introducción de dicha medida sea necesaria para el establecimiento de dicha unión aduanera. Una medida de salvaguardia que excluyera a los restantes miembros de un acuerdo de esta naturaleza no cumpliría con ninguna de dichas condiciones ${ }^{37}$.

\section{LA RELACIÓN ENTRE EL ARTÍCULO XXIV Y XIX DEL GATT EN LOS GRUPOS ESPECIALES}

En los aspectos concernientes a la relación existente entre el artículo XIX y el artículo XXIV, el Sistema de Solución de Diferencias del GATT, así como el de la OMC, no han otorgado una respuesta frontal a este respecto. En el seno del GATT, la alta sensibilidad política que supone la imposición de salvaguardias, y la exposición consecuencial a que las Partes Contratantes no adoptaran el informe pueden haber contribuido decididamente a esta cuestión ${ }^{38}$. En efecto, la delegación de Hong Kong planteó una diferencia en contra de una medida de salvaguardia impuesta por Noruega frente a las importaciones de ciertos productos textiles provenientes de aquel, excluyendo de dicha medida a los países de la EFTA, las CCEE y seis países más con los que Noruega había celebrado acuerdos bilaterales. Sin embargo, dentro de su propia argumentación, la delegación indicó que aun cuando no está de acuerdo con la explicación de la delegación noruega en torno a la exclusión de

\footnotetext{
36 Turquia - Restricciones a las Importaciones de Productos Textiles y de Vestido (WT/DS34/AB/R), Informe del Órgano de Apelación de 22 de octubre de 1999, párrafo 48; GobBi Estrella y Horlick (2006) p. 135.

37 Turquia - Textiles (WT/DS34/AB/R), Informe del Órgano de Apelación, párrafo 48; PAUwelYN (2004) p. 141. En efecto, el Grupo Especial relativo al asunto Estados Unidos - Tubos señaló que en el contexto de una zona de libre comercio, en materia de salvaguardias no era aplicable el criterio de necesidad cuando la presunta infracción del GATT de 1994 es consecuencia de la eliminación de "derechos de aduana y demás reglamentaciones comerciales restrictivas", dado que ello constituye la razón de ser de una zona de libre comercio. Según veremos, esta constatación fue revocada por el Órgano de Apelación.

38 Dentro del marco del sistema de solución de diferencias del sistema GATT/OMC, uno de los cambios más importantes consistió en la eliminación del derecho de las partes de bloquear la constitución de los Grupos Especiales, así como la adopción de los informes de estos, salvo que exista consenso para no establecer el Grupo Especial (Art. 6.1 del Entendimiento relativo a la Solución de Diferencias, o para no adoptar el informe (Arts. 16.4 y 17.14 del mismo Entendimiento), cuestión que se suele denominar la regla del "consenso negativo" o derecho colectivo de veto. Esta innovación ha hecho que la adopción de los informes por parte del Órgano de Solución de Diferencias se constituya como un mero ritual de formalidad en la OMC. Durante la época del GATT, bastaba con que uno de los Estados parte rechazara formalmente el informe del Grupo Especial para que este no fuera adoptado ( $\mathrm{Al}$ respecto puede verse Delpiano (2011) 213 y ss.).
} 
los países EFTA y CCEE, la base de su alegación no requería una resolución del panel en este punto. Sin embargo, en relación con la exclusión de los restantes seis Estados, agregó que ninguno de los seis acuerdos fue celebrado bajo el amparo de disposición alguna del GATT, de manera que al prohibir el artículo XI la restricción de importaciones, estos acuerdos no tienen asidero bajo el GATT ${ }^{39}$. De esta manera, el panel no tuvo la necesidad de abocarse a esta cuestión, sino que solo a constatar que "a finding concerning the exclusion from the quotas of the EEC and the EFTA countries was not necessary" ${ }^{40}$. Durante la vigencia del GATT se registraron otros numerosos casos de aplicación de medidas de salvaguardia de manera discriminatoria, sin que se lograra tampoco una resolución definitiva al respecto, y a su vez, se registraron algunos en que las medidas se aplicaron de una manera no discriminatoria ${ }^{41}$.

En el seno de la OMC, por su parte, sigue pendiente la cuestión acerca de si el artículo XXIV del GATT impide la aplicación de un Estado de una medida de salvaguardia a otro socio de un acuerdo de libre comercio, o bien, si deben las importaciones regionales sujetarse a medidas de salvaguardia a pesar de la norma del artículo XXIV ${ }^{42}$. El Órgano de Apelación, según veremos en el apartado siguiente, ha sostenido la doctrina del paralelismo, revocando con ello las constataciones que los Grupos Especiales han desarrollado en la relación entre el Artículo XIX y el Artículo XXIV del GATT. Sin embargo, estimamos necesario detenerse en las alternativas que los Grupos Especiales han ofrecido en la relación existente entre ambas normas.

Un primer elemento a considerar desde la jurisprudencia OMC, consiste en la constatación relativa a que la regulación sobre salvaguardias no se encuentra solo en el artículo XIX del GATT, sino que además en el Acuerdo sobre Salvaguardias. Sobre esta base, cualquier medida de salvaguardia debe cumplir, de manera acumulativa, con ambos acuerdos ${ }^{43}$. Bajo este mismo razonamiento, si entendemos que el artículo XXIV podría invocarse como defensa frente a la violación del artículo XIX del GATT, también puede invocarse como

39 En efecto, la defensa de Noruega para excluir las importaciones provenientes de los países de la EFTA y de las CCEE se fundamentaban justamente en que habían celebrado acuerdos con dichas entidades bajo el amparo del Artículo XXIV del GATT (Norway's Article XIX Action on Certain Textile Products, Report of the panel, L/4959 de 24 de marzo de 1980, párrafos 6 y 12).

40 Norway's Article XIX Action on Certain Textile Products, Report of the panel, L/4959 de 24 de marzo de 1980, párrafo 14 a). Véase también WTO Analytical Index: GATT Article XXIV, p. 844.

41 Para la primera hipótesis véanse los documentos señalados en WTO Analytical Index: GATT Article XXIV, notas 250 a 253, ambas inclusive. Para la segunda hipótesis, véase la nota 254 al mismo documento.

42 Con carácter general, si la medida de salvaguardia se aplica tanto a terceros Estados como a las importaciones regionales de una manera no discriminatoria (cumpliendo de esta manera con la norma del artículo 2.2 del Acuerdo sobre Salvaguardias), no existe necesidad de invocar el artículo XXIV del GATT como justificación, debido a que la controversia acerca de la exclusión de un Estado parte de un acuerdo de libre comercio de una salvaguardia global sería objeto de controversia en el foro regional, y no en el multilateral. Por el contrario, la cuestión de si el artículo XXIV impide salvaguardias intrarregionales puede salir a la luz en cualquier otra clase de diferencia en que el demandado intente justificar una medida contraria a las normas OMC invocando el artículo XXIV.

43 Argentina - Medidas de Salvaguardia Impuestas a las Importaciones de Calzado (WT/DS121/AB/R), Informe del Órgano de Apelación de 14 de diciembre de 1999, párrafo 84. Cabe mencionar que esta discusión se produjo en los primeros asuntos relativos a la impugnación de medidas de salvaguardia, debido a que el requisito del "aumento imprevisto" de las importaciones se encuentra expresamente establecido en el artículo XIX del GATT, pero no en el Acuerdo sobre Salvaguardias de la OMC [Véase en este sentido Matsushita et al. (2006) p. 441]. 
defensa frente a la violación de una norma del Acuerdo sobre Salvaguardias, especialmente frente al artículo $2.2^{44}$.

Sin embargo, la jurisprudencia de la $\mathrm{OMC}$ en este punto no es clara. En los casos que se ha señalado esta cuestión al Órgano de Apelación, este ha esquivado hábilmente su pronunciamiento. En efecto, en el caso Argentina - Calzado, el Grupo Especial consideró que el párrafo 8 del artículo XXIV por sí mismo no prohíbe necesariamente la aplicación de medidas de salvaguardias entre los territorios constitutivos de una unión aduanera o una zona de libre comercio durante su formación o una vez que estas se hayan establecido. El Grupo Especial apunta a que la relación entre la aplicación de medidas de salvaguardia y el requisito de liberalizar "lo esencial de los intercambios comerciales" del artículo XXIV debe ser vista en su aplicación práctica. En efecto, si bien el hecho que una medida de salvaguardia recaiga sobre una determinada categoría de productos similares no obsta necesariamente al concepto de "lo esencial", un uso amplio de estas medidas en el marco de zonas de integración regional durante períodos prolongados sí puede ser contrario al concepto de lo esencial, de manera que la lectura conjunta de la omisión del artículo XIX dentro de las excepciones al párrafo 8 con el requisito de eliminar los derechos de aduana y las demás reglamentaciones comerciales restrictivas "con respecto a lo esencial de los intercambios comerciales" dentro de una unión aduanera deja abierta tanto la posibilidad de abolir como de aplicar medidas de salvaguardia a los Estados miembros de la misma ${ }^{45}$.

Esta constatación, sin embargo, fue revocada por el Órgano de Apelación. En efecto, en su informe al respecto, señaló que la premisa sobre la que se sustentó el análisis del Grupo Especial de la aplicación de la nota al párrafo 1 del artículo 2 del Acuerdo sobre Salvaguardias al caso no era correcta. A mayor abundamiento, consideró que dicha nota no tenía aplicación al caso, desde el momento que todo el proceso de aplicación de salvaguardias fue realizado por Argentina, y no por el MERCOSUR en su nombre, de manera que no cabía dentro de las hipótesis de la nota al párrafo 1, por lo que revocó sus constataciones en este sentido. Además, teniendo en consideración que la Argentina no invocó el artículo XXIV como defensa ante la constatación de una violación del GATT de 1994, también revocó sus conclusiones en este sentido ${ }^{46}$.

En el asunto Estados Unidos - Tubos, el Órgano de Apelación evitó pronunciarse acerca de si el artículo XXIV permite excluir de una medida las importaciones procedentes de un miembro de una zona de libre comercio apartándose de lo dispuesto en el párrafo 2 del artículo 2 del Acuerdo sobre Salvaguardias. Sin embargo, agregó que "la cuestión de si el artículo XXIV del GATT de 1994 sirve como excepción al párrafo 2 del artículo 2 del Acuerdo sobre Salvaguardias solo resulta pertinente en dos posibles circunstancias. Una se da cuando en la investigación realizada por las autoridades competentes de un Miembro de la OMC las importaciones que están excluidas de la medida de salvaguardia no son tomadas en consideración en la determinación del daño grave. La otra se da cuando, en esa

44 Estados Unidos - Medidas de Salvaguardia Definitiva contra las Importaciones de Tubos al Carbono Soldados de Sección Circular Procedentes de Corea (WT/DS202/R), Informe del Grupo Especial de 29 de octubre de 2001, párrafo 7.150 .

45 Argentina - Calzado (WT/DS121/R), Informe del Grupo Especial, párrafo 8.97.

46 Argentina - Calzado (WT/DS121/AB/R), Informe del Órgano de Apelación, párrafos 106 a 110. 
investigación, las importaciones que están excluidas de la aplicación de la medida de salvaguardia son tomadas en consideración en la determinación del daño grave $y$ las autoridades competentes también han establecido explícitamente, mediante una explicación razonada y adecuada, que las importaciones procedentes de fuentes ajenas a la zona de libre comercio satisfacían, por sí solas, las condiciones para la aplicación de una medida de salvaguardia, conforme a lo establecido en el párrafo 1 del artículo 2 y desarrollado en el párrafo 2 del artículo $4{ }^{\prime 4}$.

El Grupo Especial, además, había constatado que la alegación de Corea consistía en que la exclusión de Canadá y México de la medida de salvaguardia era discriminatoria y consecuencialmente contraria al principio Nación Más Favorecida establecida en el GATT y en el Acuerdo sobre Salvaguardias, abordando, por primera vez, hasta qué punto Estados Unidos podía invocar como defensa el artículo XXIV del GATT.

En este sentido, agregó que la exclusión de las importaciones procedentes de Canadá y México de la medida de salvaguardia es parte de la eliminación de los "derechos de aduana y demás reglamentaciones restrictivas" entre los miembros del TLCAN, por lo que en principio se encuentran autorizadas por el párrafo 5 del artículo XXIV en la medida que cumplan las condiciones pertinentes ${ }^{48}$.

De esta manera, y siguiendo con el razonamiento del Órgano de Apelación en el caso Turquía - Textiles, el Grupo Especial se abocó a las condiciones para poder invocar como defensa el artículo XXIV frente al incumplimiento de una disposición del GATT ${ }^{49}$, que contienen un análisis sobre el principio de necesidad. Sin embargo, en el razonamiento del Grupo Especial en este asunto, para el caso de una zona de libre comercio, y en el contexto de una medida de salvaguardia, no es necesario aplicar un criterio de necesidad

47 Estados Unidos - Tubos (WT/DS202/AB/R), Informe del Órgano de Apelación, párrafo 198. Agregó que ninguno de estos dos supuestos se daba en este caso.

48 El informe agrega que "Con arreglo a los párrafos 5 y 8 del artículo XXIV, las condiciones pertinentes son que el TLCAN debe 1) satisfacer lo dispuesto en los párrafos 5 b) y 5 c) del artículo XXIV, y 2) eliminar los derechos y otras reglamentaciones comerciales restrictivas con respecto a 'lo esencial de los intercambios comerciales' de los productos objeto de comercio dentro de la zona del TLCAN" (Estados Unidos - Tubos (WT/ DS202/R), Informe del Grupo Especial, párrafo 7.141). En la nota al pie correspondiente a esta constatación, agregó que "El párrafo 5 del artículo XXIV especifica que no se impedirá el 'establecimiento' de una zona de libre comercio. No creemos que esto restrinja necesariamente la defensa basada en el artículo XXIV a las medidas de salvaguardia (con exclusión de los asociados en la zona de libre comercio) introducidas cuando se establece una zona de libre comercio. A nuestro juicio, basta con que el mecanismo que prevea la exclusión de los asociados en la zona de libre comercio de la aplicación de las medidas de salvaguardia (es decir, que prevea la infracción a la cláusula Nación Más Favorecida frente a la que se requiere la defensa) se cree con ocasión del establecimiento de la zona de libre comercio. En ese sentido, observamos que las importaciones procedentes del Canadá y México se excluyeron del ámbito de aplicación de la medida referente a los tubos sobre la base del artículo 802 del TLCAN, disposición incluida en el TLCAN cuando se estableció la zona de libre comercio".

49 Las condiciones impuestas en el asunto Turquía - Textiles, consisten, según señalamos supra, en que se demuestre que la medida impugnada se introdujo con ocasión del establecimiento de una unión aduanera que cumple con las prescripciones del párrafo 8 y 5 del artículo XXIV, y que se demuestre que si no se le permitiera introducir la medida impugnada se impediría el establecimiento de esa unión aduanera. Para poder invocar el artículo XXIV como defensa deben cumplirse ambas condiciones (Turquía - Textiles (WT/DS34/AB/R), Informe del Órgano de Apelación, párrafo 58). Una crítica a estas condiciones o test de compatibilidad puede verse en Pauwelyn (2004) p. 132, así como también en Kuijper (2010) p. 21. 
cuando la presunta infracción del GATT de 1994 es consecuencia de la eliminación de "derechos de aduana y demás reglamentaciones comerciales restrictivas" entre las partes en una zona de libre comercio, porque ello constituye precisamente la razón de ser de una zona de libre comercio. Si la presunta infracción del GATT de 1994 forma parte de la "eliminación de derechos de aduana y demás reglamentaciones comerciales restrictivas", no cabe duda que es necesaria para dicha eliminación ${ }^{50}$.

El Grupo Especial también señaló que era aplicable a una zona de libre comercio lo dispuesto en la frase final de la nota al párrafo 1 del artículo 2 del Acuerdo sobre Salvaguardias. En efecto, constató que dicha nota hace referencia a la relación existente entre el artículo XIX y el párrafo 8 del artículo XXIV, abarcando de esta manera a ambas formas de integración económica. "Por consiguiente, aunque las primeras tres frases de la nota 1 de pie de página contemplan la aplicación de medidas de salvaguardia en el contexto de una unión aduanera, la referencia más amplia en la última frase al párrafo 8 amplía la cobertura de esa última frase de modo que incluye la aplicación de medidas de salvaguardia en el contexto de las zonas de libre comercio, tal como se definen en el párrafo 8 b) del artículo XXIV"51.

Siendo ello así, el Grupo Especial se abocó a la cuestión acerca de la repercusión de la última frase de la nota al párrafo 1 del artículo del Acuerdo sobre Salvaguardias en la obligación de no discriminación contenida en el párrafo 2 del mismo artículo. En este sentido, la primera constatación que realiza es el hecho que la frase comienza con la expresión "Ninguna disposición del presente acuerdo", lo que quiere señalar que la referencia se hace al Acuerdo sobre Salvaguardias en su conjunto, y no solo al artículo $2^{52}$. De esta manera, y junto con la constatación que el artículo XXIV puede ser utilizado como defensa frente a las alegaciones basadas en el artículo XIX ${ }^{53}$ y que el párrafo 2 del artículo 2 del Acuerdo sobre Salvaguardias no prejuzga la relación existente entre el artículo XIX y el artículo XXIV, lleva también a la conclusión que el artículo XXIV puede ser invocado como defensa frente a las alegaciones de discriminación de conformidad con el párrafo 2 ya señalado ${ }^{54}$.

Estas constataciones fueron revocadas por el Órgano de Apelación, el que en su reemplazo antepuso el criterio de paralelismo como paso previo al análisis de la relación entre el artículo XIX y el artículo XXIV del GATT, según veremos seguidamente.

\section{EL PARALELISMO COMO PARÁMETRO DE CUMPLIMIENTO DE LA MEDIDA DE SALVAGUARDIA EN EL ÓRGANO DE APELACIÓN}

El debate acerca de la vinculación existente entre el artículo XIX y el artículo XXIV del GATT ha estado presente en diversos asuntos conocidos por los Grupos Especiales y el Órgano de Apelación. Sin embargo, este último ha evadido la cuestión de si el artículo

\footnotetext{
50 Estados Unidos - Tubos (WT/DS202/R), Informe del Grupo Especial, párrafo 7.148.

51 Estados Unidos - Tubos (WT/DS202/R), Informe del Grupo Especial, párrafo 7.153 (Subrayado en el original).

52 Estados Unidos - Tubos (WT/DS202/R), Informe del Grupo Especial, párrafo 7.157.

53 Constatación que afecta a la interpretación de la relación existente entre el artículo XIX y el artículo XXIV, ya que implica que en determinadas circunstancias el artículo XXIV puede prevalecer por sobre el artículo XIX (Ibídem, párrafo 7.158).

54 Estados Unidos - Tubos (WT/DS202/R), Informe del Grupo Especial, párrafo 7.158.
} 
XXIV puede ser invocado como defensa para justificar la aplicación discriminatoria de medidas de salvaguardia a aquellos Estados que no formen parte de un acuerdo de libre comercio. En su lugar, el Órgano de Apelación ha establecido un requisito previo de compatibilidad de la aplicación discriminatoria de medidas de salvaguardia, invocando lo que se ha denominado el "principio del paralelismo" 55 , que ha sido desarrollado en diversos asuntos.

El primer paso fue mencionado a partir del asunto Argentina - Calzados, en el que las Comunidades Europeas alegaron que entre la investigación y la aplicación de medidas de salvaguardias debe existir una relación de coherencia. En efecto, se discutía el hecho que dentro de la investigación llevada a cabo por las autoridades argentinas, el análisis para la determinación del daño a la industria doméstica haya tenido en cuenta las cifras de todas las importaciones, incluyendo las de países del MERCOSUR y las de aquellos países que no son miembros del MERCOSUR. Sin embargo, la medida de salvaguardia subsiguiente excluyó a los primeros. De esta manera, las Comunidades Europeas no discuten la exclusión de los países del MERCOSUR de la medida de salvaguardia. Sin embargo, "esa exclusión hubiera debido necesariamente entrañar la exclusión de las importaciones del MERCOSUR de los análisis relativos al 'aumento de las importaciones', al 'daño grave' y la 'causalidad', como establece el párrafo 1 del artículo 2 del Acuerdo sobre Salvaguardias" ${ }^{\text {" } 6 .}$

De esta forma, la cuestión que surge es si acaso debe existir un paralelismo entre el proceso de investigación que tiene por consecuencia la aplicación, y de otra parte, la aplicación propiamente tal de la salvaguardia. En otras palabras, si se impone una medida de salvaguardia a las importaciones procedentes ajenas a una unión aduanera -de conformidad con este argumento-, los análisis de la existencia o amenaza del daño y la relación de causalidad deben limitarse asimismo a las importaciones que no proceden de dicha unión aduanera $^{57}$. Dicho en términos económicos, el principio de paralelismo prohíbe cualquier asimetría en la aplicación de medidas de salvaguardia ${ }^{58}$.

El Órgano de Apelación, sin pronunciarse sobre la cuestión de si el miembro de una unión aduanera puede excluir a otros miembros de esa unión aduanera de una medida de salvaguardia, señaló que la investigación realizada por un Estado sobre las importaciones procedentes de todas las fuentes causan o amenazan causar un daño grave, solo puede dar

55 El principio de paralelismo, según ha señalado recientemente un Grupo Especial, "busca evitar la exclusión de la aplicación de la medida de orígenes que en conjunto contribuyen de manera significativa al daño de la industria nacional" (República Dominicana - Medidas de Salvaguardia sobre las Importaciones de Sacos de Prolipropileno y Tejido Tubular (WT/DS415/R, WT/DS416/R, WT/DS417/R, WT/DS418/R), Informe del Grupo Especial de 31 de enero de 2012, párrafo 7.384).

56 En otras palabras, las CCEE no cuestionan el derecho que tiene un miembro de una unión aduanera de excluir a otro miembro de esa unión aduanera del ámbito de una medida de salvaguardia. Lo que objeta es utilizar las importaciones de esa unión aduanera en el análisis del aumento de las importaciones cuando no existe posibilidad de incluir esas importaciones en el ámbito de la medida de salvaguardia (Argentina - Calzado (WT/ DS121/R), Informe del Grupo Especial, párrafos 5.67 y 5.68).

57 Argentina - Calzado (WT/DS121/R), Informe del Grupo Especial, párrafo 8.80. Estas constataciones, sin embargo, fueron revocadas por el Órgano de Apelación, debido a que entendió que la medida había sido aplicada por Argentina, y no por el MERCOSUR en su nombre, con lo que agregó una tercera posibilidad a la aplicación de salvaguardias en una unión aduanera (PAUWELYN (2004) p. 116; Argentina - Calzado (WT/DS121/ $\mathrm{AB} / \mathrm{R})$, Informe del Órgano de Apelación, párrafo 106).

58 TeH et al. (2009) p. 237. 
Delpiano LiRA, Cristián — "Medidas de salvaguardia y exclusiones regionales en la jurisprudencia ..."

lugar a la aplicación de medidas de salvaguardia a las importaciones procedentes de todas las fuentes. De esta forma, "Argentina no puede justificar [...] la aplicación de sus medidas de salvaguardia solo a las fuentes de suministro de terceros países que no son miembros del MERCOSUR basándose en una investigación que constató la existencia o amenaza de daño grave causado por importaciones procedentes de todas las fuentes, con inclusión de las importaciones procedentes de otros Estados miembros del MERCOSUR" 59 . En consecuencia, el Órgano de Apelación exige que entre la investigación y la aplicación de la medida de salvaguardia exista un cierto grado de coherencia.

En la diferencia Estados Unidos - Gluten de Trigo, se discutió la exclusión de importaciones procedentes de un Estado del ámbito de aplicación de la salvaguardia, después de haber realizado una investigación inicial en las importaciones procedentes de todas las fuentes, y luego una investigación adicional centrada específicamente en las importaciones de dicho Estado ${ }^{60}$. El Órgano de Apelación consideró que para que constituya base suficiente de exclusión de un Estado de la aplicación de la medida de salvaguardia, la investigación debe establecer, explícitamente, que las importaciones de estas mismas fuentes con exclusión de las importaciones del Estado a que se va a eximir de la aflicción de la medida, cumplen las condiciones del párrafo 1 del artículo 2 del Acuerdo sobre Salvaguardias $^{61}$. Por su parte, en los asuntos Estados Unidos - Carne de Cordero y Estados Unidos - Tubos señaló que para que una afirmación sea explícita, la autoridad competente debe facilitar "una explicación razonada y adecuada del modo en que los factores corroboran su

59 Argentina-Calzado (WT/DS121/AB/R), Informe del Órgano de Apelación, párrafo 114.

60 Estados Unidos - Medidas de Salvaguardia Definitivas Impuestas a las Importaciones de Gluten de Trigo Procedentes de las Comunidades Europeas (WT/DS166/AB/R), Informe del Órgano de Apelación de 22 de diciembre de 2000, párrafo 97.

${ }^{61}$ Estados Unidos - Gluten de Trigo (WT/DS166/AB/R), Informe del Órgano de Apelación, párrafo 98. En este caso, Estados Unidos había impuesto una medida de salvaguardia a las importaciones de Gluten de Trigo, excluyendo de esta medida a Canadá, a la sazón su socio comercial en el NAFTA. De esta manera, Estados Unidos alegó que la exclusión del Canadá de la medida de salvaguardia es compatible con el artículo XXIV, señalando que la última oración de la nota al párrafo 1 del artículo 2 del Acuerdo sobre Salvaguardias contiene disposiciones específicas relativas a la aplicación de estas medidas por los miembros de una unión aduanera o una zona de libre comercio, sin llegar a constituir una excepción al párrafo 2 del mismo artículo. El Grupo Especial, sin embargo, eludió el análisis propuesto, argumentando que "los Estados Unidos no alegan que el artículo XXIV del GATT de 1994 les ofrece defensa frente a la acusación de vulneración de una disposición del Acuerdo sobre Salvaguardias". En todo caso, señaló que "no interpretamos que la última oración de la nota 1 del Acuerdo sobre Salvaguardias establezca que la cuestión de cómo puede/debe tratar un miembro de una zona de libre comercio a las importaciones procedentes de un socio en esa zona de libre comercio no se pueda resolver mediante referencia al Acuerdo sobre Salvaguardias, sino mediante referencia únicamente a los artículos XXIV y XIX del GATT. Como ya hemos indicado, creemos que la simetría que hemos constatado que exigen el párrafo 1 del artículo 2 y el párrafo 2 del artículo 4 del Acuerdo sobre Salvaguardias entre el ámbito de los productos importados sometidos a investigación y el ámbito de los productos importados sometidos a la aplicación de la medida es también pertinente en este contexto. La nota 1 del Acuerdo sobre Salvaguardias no modifica nuestra opinión", pudiendo pronunciarse sobre la alegación de las CCEE sin recurrir al artículo XXIV ni a la nota 1 del Acuerdo sobre Salvaguardias. El Órgano de Apelación no formuló ninguna constatación sobre este argumento, considerando que el enfoque "no era erróneo" (Estados Unidos - Medidas de Salvaguardia Definitivas Impuestas a las Importaciones de Gluten de Trigo Procedentes de las Comunidades Europeas (WT/DS166/R), Informe del Grupo Especial de 31 de julio de 2000, párrafo 8.181, y Estados Unidos - Gluten de Trigo (WT/DS166/ AB/R), Informe del Órgano de Apelación, párrafo 99). 
determinación" ${ }^{2}$, expresando "de manera precisa todo lo que quiere decir, no debe dejar nada meramente implícito o insinuado, tiene que ser clara e inequívoca" ${ }^{63}$. Dentro de la explicación razonada y adecuada, "debe establecer si las importaciones incluidas en la medida de salvaguardia satisfac[en] por sí solas los requisitos para la imposición de una medida de salvaguardia, [debiendo tener] en cuenta el posible daño causado por las importaciones procedentes de fuentes excluidas" ${ }^{64}$.

Lo interesante de los razonamientos explicados es que, al menos en principio, al Órgano de Apelación le habría bastado con constatar que las medidas de salvaguardia se aplicaron a las importaciones procedentes de terceros Estados excluyendo a las importaciones procedentes de Estados parte de los socios de los acuerdos comerciales en contravención a la disposición del artículo 2.2 del Acuerdo sobre Salvaguardias. Con ello, habría reconocido que la regla general es que las medidas de salvaguardia deben ser aplicadas bajo el régimen Nación Más Favorecida, sin permitir en ningún caso una implementación discriminatoria de las mismas. Sin embargo, anteponiendo el criterio de paralelismo, reconoce que bajo ciertos supuestos -que no señala- pueden ser aplicadas medidas de salvaguardia de manera discriminatoria ${ }^{65}$.

De estos criterios expuestos, surge la pregunta acerca del establecimiento mismo del criterio del paralelismo, así como si el solo cumplimiento del requisito de paralelismo puede servir para justificar la exclusión de un Estado miembro de la OMC bajo el amparo del artículo XXIV, o incluso al margen de que sean o no parte de un acuerdo de libre comercio. Por último, surge la pregunta de si el cumplimiento del requisito de paralelismo -y la

62 Estados Unidos - Medidas de Salvaguardia respecto de las Importaciones de Carne de Cordero Fresca, Refrigerada o Congelada Procedentes de Nueva Zelandia y Australia, (WT/DS177/AB/R y WT/DS178/AB/R), Informe del Organo de Apelación de 1 de mayo de 2001, párrafo 103.

${ }_{63}$ Estados Unidos - Medidas de Salvaguardia Definitiva contra las Importaciones de Tubos al Carbono Soldados de Sección Circular Procedentes de Corea (WT/DS202/AB/R), Informe del Órgano de Apelación de 15 de febrero de 2002, párrafo 194. A ello cabe agregar la constatación del Órgano de Apelación en relación con la expresión "importación de ese producto" del párrafo 1 del artículo 2, y la expresión "producto importado" del párrafo 2 del mismo artículo. En efecto, el Órgano de Apelación consideró que ambas expresiones se refieren al mismo texto en ambas disposiciones, por lo que tienen también el mismo sentido (Estados Unidos - Gluten de Trigo (WT/DS166/AB/R), Informe del Órgano de Apelación, párrafo 96 junto con la nota al pie de dicho párrafo).

${ }^{64}$ Estados Unidos - Medidas de Salvaguardia Definitivas sobre las Importaciones de Determinados Productos de Acero (WT/DS248/AB/R - WT/DS249/AB/R - WT/DS251/AB/R - WT/DS252/AB/R - WT/DS253/AB/R - WT/DS254/AB/R - WT/DS258/AB/R - WT/DS259/AB/R), Informe del Órgano de Apelación de 10 de noviembre de 2003, párrafo 456 (Cursivas en el original). Los países excluidos fueron Canadá, México (Estados Parte del NAFTA), Israel y Jordania. Esta cuestión, tal como la planteó la delegación de Estados Unidos, se denomina la "prescripción de cómputo de las fuentes excluidas". Este requisito, además, no puede cumplirse a través de una serie de determinaciones separadas y parciales, sino que debe facilitarse a través de una única determinación conjunta (Estados Unidos - Acero (WT/DS248/AB/R - WT/DS249/AB/R - WT/DS251/AB/R - WT/ DS252/AB/R - WT/DS253/AB/R - WT/DS254/AB/R - WT/DS258/AB/R - WT/DS259/AB/R), Informe del Órgano de Apelación, párrafos 466 y 468).

65 Salvo que el fundamento para la exclusión de un Estado miembro sea la regla especial sobre trato diferenciado y más favorable relativo a los países en desarrollo establecido en el artículo 9.1 del Acuerdo sobre Salvaguardias de la OMC, caso en el cual no se aplica el requisito de paralelismo. Véase en este sentido República Dominicana - Medidas de Salvaguardia sobre las Importaciones de Sacos de Prolipropileno y Tejido Tubular (WT/ DS415/R, WT/DS416/R, WT/DS417/R, WT/DS418/R), Informe del Grupo Especial de 31 de enero de 2012, párrafos 7.371 y ss. 
DelpiAno LiRA, Cristián — "Medidas de salvaguardia y exclusiones regionales en la jurisprudencia ..."

consecuente exclusión de productos originarios de un Estado parte de un acuerdo de libre comercio de la etapa de investigación- puede distorsionar la razón por la cual se impone una medida de salvaguardia. A mayor abundamiento, la imposición de una medida de salvaguardia se justifica en la recuperación de la competitividad de los productores nacionales afectados por un aumento imprevisto de las importaciones de productos similares o directamente competidores, y por tanto como medida urgente y temporal. No se justifica, por el contrario, en la protección que el Estado haya de brindar a sus productores nacionales frente a casos de competencia desleal, como son los casos de investigaciones Antidumping o de medidas compensatorias.

Para Pauwelyn, la "contorsión innecesaria" en torno al paralelismo puede tener explicación en que tanto los Grupos Especiales como el Órgano de Apelación han buscado sortear la "adivinanza no resuelta" de si acaso el artículo XXIV en relación con los acuerdos regionales pueden justificar una medida de salvaguardia discriminatoria en violación al artículo 2.2 del Acuerdo sobre Salvaguardias ${ }^{66}$. Es de hacer notar en este sentido que tanto en los asuntos Argentina - Calzados como en Estados Unidos - Tubos, se invocó como defensa el artículo XXIV, pero en ambos el Órgano de Apelación evadió la cuestión, considerando que se había violado el principio de paralelismo.

En otras palabras, según el criterio del Órgano de Apelación, el artículo XXIV solo sería analizado cuando el principio del paralelismo haya sido respetado, en particular cuando se demuestra que las importaciones de terceros Estados por sí mismo causan o amenazan causar grave daño y la medida eventual de salvaguardia, de esta manera, excluye a las importaciones regionales. Desde esta perspectiva, puede concluirse que el artículo XXIV del GATT nunca puede justificar una violación al principio del paralelismo, aunque el Órgano de Apelación nunca ha explicado por qué se da este efecto. A mayor abundamiento, si el Órgano de Apelación deja abierta la cuestión de si acaso puede justificarse por el artículo XXIV una violación del principio de no discriminación del artículo 2.2 del Acuerdo sobre Salvaguardias, surge la pregunta acerca de por qué el artículo XXIV no sirve como justificación para violar el principio del paralelismo, que, al final de cuentas, emana también del propio artículo 2 del Acuerdo sobre Salvaguardias. Estas cuestiones, en todo caso, pueden responder a un debate más amplio, consistente en si acaso el artículo XXIV puede servir para justificar una violación a las normas de los acuerdos especializados relacionados con el GATT, tales como el Acuerdo sobre Salvaguardias ${ }^{67}$.

66 Pauwelyn (2004) p. 121. La constatación hace referencia a que el artículo 2.2 exige que la medida se aplique al producto importado independientemente de la fuente de que proceda. AHN, por su parte, señala que el Órgano de Apelación, al enfrentar esta cuestión, la ha hecho depender del concepto inventado de paralelismo, funcionando como una de las disciplinas más severas para atacar todas las medidas de salvaguardia revisadas [AHN (2006) p. 20].

${ }_{67}$ PAuWelyn (2004) p. 122. En el mismo sentido SyKes (2006) p. 226 y ss. PAUWelyn agrega que la exigencia de paralelismo plantea algunos problemas adicionales. En concreto, investigar todas las importaciones mientras se aplica la medida de salvaguardia solo a terceros Estados de un acuerdo de libre comercio no sería la única violación a este principio que se pudiera pensar. Si el paralelismo es el requisito objetivo de equivalencia en las importaciones considerado en los artículos 2.1 y 2.2 del Acuerdo sobre Salvaguardias, entonces también la investigación de las importaciones provenientes por ejemplo de un solo Estado seguido de una medida de salvaguardia a las importaciones de todas las fuentes también lo sería. Sin embargo, cabe la duda en relación a si 
El sentido del artículo 2.2 del Acuerdo sobre Salvaguardias del GATT consiste, en definitiva, en que a pesar que las importaciones provenientes de un solo Estado miembro puedan provocar un grave de daño a una rama de producción nacional, las medidas de salvaguardias deben establecerse en relación con el producto, de manera de evitar medidas de salvaguardias selectivas. En palabras de PAUWELYN, la inclusión del principio del paralelismo en el análisis de una medida de salvaguardia, más que ayudar a resolver la cuestión de la justificación de una medida de salvaguardia bajo el amparo del artículo XXIV, ha agudizado el problema, dado el conflicto que se genera entre este principio y el de no discriminación ${ }^{68}$.

A ello cabe agregar que la interpretación del Órgano de Apelación sugiere una respuesta similar a la propuesta de mayo de 1990 emanada de la Secretaría del GATT durante las negociaciones de la Ronda Uruguay, conforme a la cual, para permitir la exclusión de los miembros de una zona de libre comercio o de una unión aduanera, el Estado miembro o la unión aduanera a nombre de un miembro debía demostrar que el grave daño que da lugar a que se invoque el artículo XIX se debe a las importaciones procedentes de países no miembros. Dicho de otra manera, la tesis del Órgano de Apelación parece ser una respuesta frente a las negociaciones de la Ronda Uruguay, imponiendo un criterio cuya propuesta no fructificó en su oportunidad. Cierto es que ni en las negociaciones ni tampoco el Órgano de Apelación han adoptado una respuesta a la relación entre el artículo XIX y el artículo XXIV del GATT, pero este último, a través del principio del paralelismo provocó como efecto un verdadero reemplazo de la propia voluntad de los Estados negociadores de la Ronda Uruguay en los parámetros a través de los cuales se mide la compatibilidad de la exclusión de un miembro de una zona de libre comercio o de una unión aduanera con las normas del GATT ${ }^{69}$.

\section{CONCLUSIONES}

No existe en el seno de la OMC un acuerdo relativo a la facultad de un Estado miembro de excluir a otros Estados miembros de la OMC que a la vez sean parte de un acuerdo de libre comercio de una medida de salvaguardia global. Esta falta de acuerdo ha permitido que dentro de este tipo de tratados se incluyan cláusulas que faculten e incluso exijan esta conducta entre socios de un acuerdo de libre comercio.

De esta manera, continúa abierto el debate relativo a la selectividad en la imposición de medidas de salvaguardias en general, y si acaso el artículo XXIV puede servir para justificar la exclusión de socios comerciales, en particular.

A pesar que algunos Grupos Especiales han intentado dar algunas alternativas de solución a esta cuestión, el Órgano de Apelación ha evadido la discusión anteponiendo el principio de paralelismo como paso previo al análisis de la relación entre el artículo XIX y

realmente se incumple el requisito previsto en el artículo XIX y en el Acuerdo sobre Salvaguardias si se investiga el daño de un producto importado proveniente de una sola fuente, y luego se aplica la medida bajo el principio Nación Más Favorecida.

68 Pauwelyn (2004) p. 123.

69 En este sentido, puede verse parte de la argumentación de Argentina en Argentina - Calzado (WT/DS121/ AB/R), Informe del Órgano de Apelación, párrafo 13. 
el artículo XXIV del GATT. Así, entendemos que el Órgano de Apelación no exige explícitamente que las medidas de salvaguardia se impongan solo al producto, con independencia del lugar de procedencia. Sin embargo, no ha explicado de manera satisfactoria en qué casos y bajo qué condiciones -al margen del cumplimiento del principio de paralelismo- se puede excluir a un Estado miembro de la OMC de una medida de salvaguardia global. Ello se suma a la confusión existente en la materia dentro del marco normativo de la OMC.

En consecuencia, podemos señalar no solo que no existe una norma que defina la relación existente entre el artículo XIX y el artículo XXIV del GATT, sino que además tampoco existen criterios definidos para una aplicación discriminatoria sobre la base del establecimiento del artículo XXIV como defensa. Probablemente este es uno de aquellos casos en el cual existe un consenso acerca del hecho que no hay consenso, lo que dificulta de una manera importante la determinación de la conducta que debe adoptar el Estado en este sentido. El Órgano de Apelación, al anteponer el principio de paralelismo como requisito previo para el análisis del alcance del artículo XXIV como defensa válida ante la imposición discriminatoria de medidas de salvaguardia, ha intentado evitar la adopción de una posición negociadora desechada en su momento, aun cuando el principio de paralelismo se asemeje en muchos aspectos a las posiciones discutidas durante la Ronda Uruguay.

\section{BIBLIOGRAFÍA CITADA}

Ahn, Dukgeun (2006): "Restructuring the WTO Safeguard System", en Mitsuo Matsushita, Dukgeun Ahn and Tain-Jy Chen (eds.): The WTO Trade Remedy System: East Asian Perspective (London, Cameron May Publishers).

Ahn, Dukgeun (2008): "Foe or Friends of Article XXIV: Diversity in Trade Remedy Rules", Journal of International Economic Law, vol. 11, N 1: pp. 107-133

Delpiano, Cristián (2011): "El Mecanismo de Solución de Diferencias de la OMC. Un Elemento de Seguridad y Previsibilidad en el Sistema Multilateral de Comercio", Revista de Derecho de la Universidad Católica del Norte, vol. 18 No 1: pp. 213-239.

Gantz, David (2009): Regional Trade Agreements. Law, Policy and Practice (Durham, Carolina Academic Press).

Gobbi Estrella, Angela; Horlick, Gary (2006): "Mandatory Abolition of Anti - Dumping, Countervailing Duties and Safeguards in Customs Unions and Free Trade Areas Constituted between WTO Members: Revisiting a Long - Standing Discussion in Light of the Appellate Body's Turkey - Textiles Ruling", en Bartels, Lorand; Ortino, Federico (eds.): Regional Trade Agreements and WTO Legal System (Oxford, Oxford University Press).

Kujper, Pieter Jan (2010): Conflicting Rules and Clashing Courts: The Case of Multilateral Environmental Agreements, Free Trade Agreements and the WTO, Issue Paper No 10, ICTSD's Programme on Dispute Settlement and Legal Aspects of International Trade (Geneva, International Centre for Trade and Sustainable Development).

Lockhart, Nicolas; Mitchell, Andrew (2005): "Regional Trade Agreements under GATT 1994: An Exceptions and its Limits", en Mrtchell, Andrew (edit.): Challenges and Prospects for the WTO (London, Cameron May).

MathIS, James (2002): Regional Trade Agreements in the GATT/WTO: Article XXIV and the Internal Trade Requirement (The Hague, TMC Asser Press). 
Matsushita, Mitsuo; Schoenbaum, Thomas; Mavroidis, Petros (2006): The World Trade Organization. Law, Practice and Policy, $2^{\text {nd }}$ Edition (Oxford, Oxford University Press).

Pauwelyn, Joost (2004): "The Puzzle on WTO Safeguards and Regional Trade Agreements", Journal of International Economic Law, Vol. 7, № 1: 109-142.

Sykes, Alan (2006): The WTO Agreement on Safeguards (Oxford, Oxford University Press).

Teh, Robert; Prusa, Thomas; Budetta, Michele (2009): “Trade Remedy Provisions in Regional Trade Agreements", en Estevadeordal, Antoni; Souminen, Kati; Teh, Robert (Eds.): Regional Rules in Global Trading System (Cambridge, Cambridge University Press).

\section{JURISPRUDENCIA CITADA}

Argentina - Medidas de Salvaguardia Impuestas a las Importaciones de Calzado (WT/ DS121/R), Informe del Grupo Especial de 25 de junio de 1999.

Argentina - Medidas de Salvaguardia Impuestas a las Importaciones de Calzado (WT/DS121/ AB/R), Informe del Órgano de Apelación de 14 de diciembre de 1999.

Estados Unidos - Medidas de Salvaguardia Definitivas Impuestas a las Importaciones de Gluten de Trigo Procedentes de las Comunidades Europeas (WT/DS166/R), Informe del Grupo Especial de 31 de julio de 2000.

Estados Unidos - Medidas de Salvaguardia Definitivas Impuestas a las Importaciones de Gluten de Trigo Procedentes de las Comunidades Europeas (WT/DS166/AB/R), Informe del Órgano de Apelación de 22 de diciembre de 2000.

Estados Unidos - Medidas de Salvaguardia Definitiva contra las Importaciones de Tubos al Carbono Soldados de Sección Circular Procedentes de Corea (WT/DS202/R), Informe del Grupo Especial de 29 de octubre de 2001.

Estados Unidos - Medidas de Salvaguardia Definitiva contra las Importaciones de Tubos al Carbono Soldados de Sección Circular Procedentes de Corea (WT/DS202/AB/R), Informe del Órgano de Apelación de 15 de febrero de 2002.

Estados Unidos - Medidas de Salvaguardia Definitivas sobre las Importaciones de Determinados Productos de Acero (WT/DS248/AB/R - WT/DS249/AB/R - WT/DS251/AB/R - WT/ DS252/AB/R - WT/DS253/AB/R - WT/DS254/AB/R - WT/DS258/AB/R - WT/ DS259/AB/R), Informe del Órgano de Apelación de 10 de noviembre de 2003.

Norway's Article XIX Action on Certain Textile Products, Report of the panel, L/4959 de 24 de marzo de 1980.

República Dominicana - Medidas de Salvaguardia sobre las Importaciones de Sacos de Prolipropileno y Tejido Tubular (WT/DS415/R, WT/DS416/R, WT/DS417/R, WT/DS418/R), Informe del Grupo Especial de 31 de enero de 2012.

Turquía - Restricciones a las Importaciones de Productos Textiles y de Vestido (WT/DS34/ AB/R), Informe del Órgano de Apelación de 22 de octubre de 1999.

\section{DOCUMENTOS CITADOS}

Comisión Europea (2006): Libro Verde. Una Europa Global: Instrumentos de Defensa Comercial Europeos en una Economía Global en Transformación, Documento COM(2006) 763 final de 6 de diciembre de 2006. 
Comunicación de Australia al Comité de Acuerdos Comerciales Regionales, WT/ REG/W/18 de 17 de noviembre de 1997.

Comunicación del Japón al Comité de Acuerdos Comerciales Regionales: Las Demás Reglamentaciones Comerciales, WT/REG/W/29 de 29 de julio de 1998.

Informe del Grupo de Trabajo sobre las Comunidades Económicas Europeas Acuerdos con Islandia, L/3902, de 19 de octubre de 1973.

Informe del Grupo de Negociación sobre las Normas (2002): Compendio de Cuestiones Relacionadas con los Acuerdos Comerciales Regionales (TN/RL/W/8/Rev.1), de 1 de agosto de 2002.

Informe del Grupo de Trabajo sobre el Acuerdo de Libre Comercio entre Estados Unidos y Canadá, L/6927 de 31 de octubre de 1991.

Nota de la Secretaría relativa al artículo XXIV del GATT, MTN.GNG/NG7/W/13/ Add.1, de 10 de julio de 1988. 